\title{
EFFECT OF TOBACCO ON ORAL-HEALTH AN OVERVIEW
}

Mubeen. K, Chandrashekhar. H, Kavitha M, Nagarathna. S.

1. Professor and Head, Department of Oral Medicine and Radiology, Government Dental College and Research Institute, Bangalore, Karnataka, India.

2. Professor and Head, Department of Psychiatry, Bangalore Medical College and Research Institute, Bangalore, Karnataka, India.

3. Post Graduate,Department of Oral Medicine and Radiology, Government Dental College and Research Institute, Bangalore, Karnataka, India.

4. Additional Professor of Neuromicrobiology, NIMHANS, Bangalore

\section{CORRESPONDING AUTHOR:}

\section{Dr. Kavitha M.}

Department of Oral Medicine and Radiology,

Government Dental College and Research Institute,

Bangalore, Karnataka, India.

E-mail: kavitha.smnsn@gmail.com

\begin{abstract}
Tobacco is the greatest disease-producing product, with its prevalent addictive habit influencing the behavior of human beings for more than four centuries. Tobacco is consumed orally in a variety of forms such as smoking and chewable forms. Smoking is increasing rapidly throughout the developing world and is one of the biggest threats to current and future world health. By 2030, if current trends continue, smoking will kill more than nine million people annually. On an average, to date $47.5 \%$ of men and $10.3 \%$ of women are smokers. In India, tobacco products are commercially available with added scents and flavouring agents which not only attracts rural population but also influences urban population. Tobacco smoking is linked with many serious illnesses, such as cardiopulmonary diseases, cancer, low birth weight, as well as with many other health problems, contributing to thousands of premature deaths each year When exposed to tobacco salivary behaviour is reversed and saliva loses its antioxidant capacity, becoming a potent pro-oxidant milieu Most oral consequences of tobacco use impair quality of life be they as simple as halitosis or as complex as oral birth defects, as common as periodontal disease or as troublesome as complications during wound healing. Tobacco smoking and chewing not only causes discolouration of teeth, periodontitis, dental caries, altered taste, nicotinic stomatitis, but also causes leukoplakia \& carcinoma with high morbidity and mortality. It is especially important to understand that harmful effects of tobacco products are dose-dependent, that they depend more on abuse than on simple use. The aim of this review is to highlight the effect of smoking and chewing forms of tobacco on oral health._and remedies which can be thought of.
\end{abstract}

Key words: Tobacco, teeth stains, periodontitis, oral submucous fibrosis oral-pre cancer, oral cancer

INTRODUCTION: The epidemic of tobacco use is one of the greatest threats to global health today. Approximately one-third of the adult population in the world use tobacco in some form and of who half will die prematurely. According to the most recent estimate by the World Health Organization (WHO), worldwide 4.9 million people died in the year 2000 as a result of their addiction to 
nicotine.In addition to several other chronic diseases, tobacco use is a primary cause of many oral diseases and adverse oral conditions. Epidemiological studies in India have shown that up to 80\% of oral cancer patients are tobacco users. Nicotine is found in substantial amount in tobacco products that makes addicts out of tobacco users. It is a stimulant with properties similar to those of cocaine and amphetamines. Nicotine is thousand times more potent than alcohol, 10-100 times more potent than barbiturates and 5-10 times more potent than cocaine or morphine in its addictive potential. The addictive effect of nicotine is linked to its capacity to trigger the release of dopamine- a chemical in the brain that is associated with feelings of pleasure. However, recent research has suggested that in the long term, it depresses the ability of the brain to experience pleasure. So, smokers and chewers need greater amounts of the drug to achieve the same levels of satisfaction. Tobacco use is therefore a form of self medication; further use relieves the withdrawal symptoms, which set in soon after the effects of nicotine wear off 1 .

Oral changes due to tobacco are 1) irritations of oral mucosa by toxins, and carcinogens found naturally in tobacco 2) mucosal drying effects, 3) high intraoral temperature, 4) change in intraoral $\mathrm{pH}, 5$ ) local alteration of membrane barriers 6)alteration in the immune response 6) altered resistance to fungal and viral infections ${ }^{2}$.

\section{FORMS OF TOBACCO}

Smoking forms: Beedi, Cigarette, Cigar, Dhumti, Gudakhu, Hookah, Hookli. ${ }^{3}$

Chewable forms: Paan, Khaini, Mainpuri tobacco, Mawa, Mishri, Snuff, Zarda. ${ }^{3}$

\section{EFFECT OF TOBACCO ON TEETH:}

\section{A. TEETH STAINS:}

Smoking forms: Tobacco stain, a brown/black extrinsic stain, is typically found on the enamel surfaces of smokers. It is especially pronounced in cervical areas and the lingual aspects of the mandibular incisors. The extent of staining depends on the duration and frequency of the habit as well as the oral hygiene of the individual. As a general rule, smokers have almost twice as much tooth staining as non-smokers. Staining of teeth is caused by retention of components of tar and nicotine on the teeth and the reaction of furfural and acetaldehyde present in tobacco smoke with the amino groups of pellicle glycoprotein ${ }^{4}$ (Fig.1).

Chewable forms: Many of the chemicals in chewable tobacco are same as that of smoked tobacco. In addition, nitrosamines, sugar, salt, flavouring agents, abrasives and other chemicals are also present in small amounts.

Betel nut has been shown to contain many chemicals like alkaloids, polyphenols, tannins, fat, polysaccharides, protein, minerals and vitamins. The most important of these are the alkaloidsarecoline and arecaidine. During chewing, betel nut alkaloids also release areca-derived $\mathrm{N}$ nitrosamines. Initially, a red coloured stain is observed due to oxidation of the polyphenols into red-coloured orthoquinones in an alkaline $\mathrm{pH}$ provided by the slaked lime. With time, It gets converted into complex polymerized end products that are brown-black in colour. Another probable mechanism may be the denaturation of pellicle proteins by the tannins and tannic acid present in areca nut. Areca nut is rich in copper and the combination of tannins and copper produce a black-brown precipitate 4 .

\section{B) DENTAL CARIES}


Smoking forms: Schmidt, in 1951, reported that the increase in tobacco smoking was followed by a decrease in caries rate 5 . Smoking increases thiocyanate level in saliva 6 , 7. Thiocyanate, a normal constituent of saliva, was found to have a possible caries inhibiting effect 8,9 .

Most recent investigators, however, have concluded that cigarette smoking is certainly associated with an increased caries rate. The decreased buffering effect of smoker's saliva and the higher number of lactobacilli and S. mutans group may indicate an increased susceptibility to caries ${ }^{8}$, 9. Studies have shown that smoking is associated with lower salivary cystatin activity and lower output of cystatin $\mathrm{C}$ during gingival inflammation. Cystatins are thought to contribute to maintaining oral health by inhibiting certain proteolytic enzymes. It has been suggested that smokers have poor oral hygiene, make fewer visits to dentists, and have lesser overall health standard than non-smokers, leading to increased caries rate, especially cervical, inter-proximal and root surface caries ${ }^{10,11 .}$

Chewable forms: More than one-fifth of the content of some brands of chewable tobacco is sugar and a few brands are even capable of serving as growth media for several bacteria implicated in the production of caries ${ }^{10,12}$. Tobacco chewers, moreover, have significantly greater numbers of cariesassociated bacteria at the site of quid placement when compared to nonusers. The caries that results from chewing tobacco is frequently cervical, inter-proximal or root caries ${ }^{13}$.

C) TOOTH ABRASIONS: Tooth abrasion resulting in a notching of incisal edges and cusp tips is a well-established consequence of holding a pipe in the same location while smoking. But long-term tobacco chewers also demonstrate excessive and frequently generalized wear of occlusal and incisal surfaces. This wear is produced by sand and other gritty materials remaining in processed tobacco 14 .

D) TOOTH EROSION. The chemical dissolution of enamel has occasionally been reported in tobacco smokers and chewers. Erosion does not seem to be a serious problem and, in fact, chewers may be somewhat protected by the natural alkalinity of smokeless tobacco ${ }^{14}$.

\section{EFFECT OF TOBACCO ON THE GINGIVA AND PERIODONTIUM:}

\section{A) GINGIVITIS:}

Smoking forms: The gingival bleeding in smokers is 'less severe' than in non-smokers ( as much as $70 \%{ }^{14}$. Tobacco smoke (i) cause acute periodontal vasoconstriction at the end-arterial vasculature of the gingiva by nicotine (ii) inhibit periodontal angiogenesis in response to inflammatory stimuli, and/or (iii) suppress the production of pro-inflammatory mediators 15 iv) suppresses human immune responses, including responses to oral microbial toxins. Smokers also have markedly more calculus than non -smokers ${ }^{14,16 .}$

Chewable forms: Tobacco chewers have an incidence of gingivitis and gingival bleeding that is similar to the incidence among non-users. Nevertheless, use of this form of tobacco is known to produce a painless loss of gingival tissues and alveolar bone destruction in the area of chronic tobacco contact, as a result of collagen breakdown due to increased release of collagenase ${ }^{17}$. Nicotine inhibits the growth of gingival fibroblasts and their production of fibronectin and collagen ${ }^{17}$. Furthermore, oral leukocytes, especially neutrophils, may exhibit diminished ability to migrate and phagocytose, and they contribute to the inactivation of tissue proteinase inhibitors ${ }^{18}$. 
B) ACUTE NECROTIZING ULCERATIVE GINGIVITIS (ANUG): ANUG is strongly correlated with tobacco use. Ninety-eight percent of ANUG patients are smokers, and persons who smoke more than ten cigarettes per day have a tenfold increase in ANUG prevalence compared to non-smoker ${ }^{20}$. ANUG occurs most frequently in teenagers and young adults and may result from defective neutrophil function allowing bacterial and possibly viral (cytomegalovirus) invasion of gingival tissues ${ }^{21}$. The vasoconstrictive action of nicotine and other tobacco components is thought to contribute strongly to the painful tissue necrosis and ulceration seen in this disease 22 .

C) EFFECT OF TOBACCO SMOKE ON PERIODONTAL TISSUES: Smokers have deeper pockets, more alveolar bone loss, tooth mobility, and greater tooth loss than non-smokers ${ }^{23-26}$. Smokers were recorded to have a 2.5 to 3.5 times greater risk of severe periodontal attachment loss. The cytotoxic substances absorbed from tobacco, especially nicotine and cotinine (its major metabolite), are found in secreted saliva and crevicular fluids. Laboratory studies suggest that the attachment of fibroblasts to cementum is altered by nicotine. In addition, emotional stress and poor oral hygiene seem to play an important interactive role with tobacco smoking ${ }^{27}$ (Fig. 1). Clot disrupting effect of negative intraoral pressure produced during smoking delays wound healing.

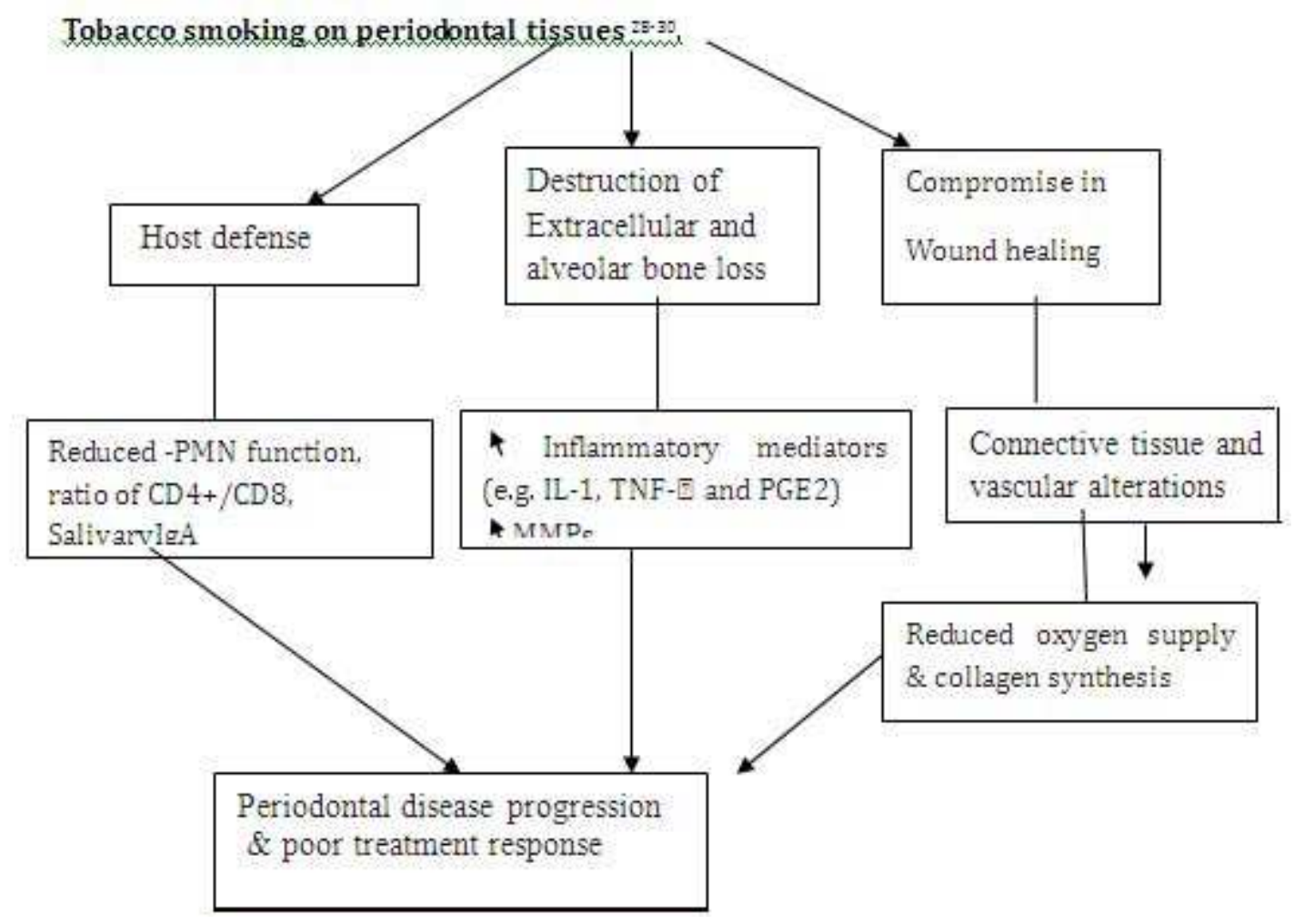

EFFECTS OF SMOKING ON PERIODONTAL THERAPY OUTCOMES: Smokers respond less favourable than non-smokers to nonsurgical ${ }^{31,32}$ and surgical periodontal therapy 33 Smokers exhibited less improvement when compared with non-smokers, in terms of pocket depth reduction, resolution of gingival inflammation, and clinical attachment level ${ }^{31,32,34}$. In addition, current smokers have poor healing ability, which is associated with persistent subgingival infection with Bacteroides 
forsythus and Porphyromonas gingivalis following sub gingival scaling and root planning when compared with ex-smokers and non-smokers 35.

CHEWABLE FORMS: Tobacco chewers are also prone to a localized periodontal destruction or recession resulting from the combination of nicotine's chemical effects and the effects of physical abrasion on local gingival tissues ${ }^{14}$.

\section{EFFECT OF TOBACCO ON THE MUCOSA:}

\section{A) STAINING OF MUCOSA:}

SMOKER'S MELANOSIS: Smoking is capable of stimulating oral mucosal melanocytes to produce excessive melanin, thereby creating patches of brown pigmentation on gingival or buccal mucosa in $5-22 \%$ of heavy smokers. The intensity of smoker's melanoses is dose-dependent. In vitro testing has demonstrated that it is the nicotine itself which activates one of the steps in melanin production. There are no symptoms, the change is not premalignant, and the pigmentation may be reversible upon cessation of smoking habit $6,8,14$.

NICOTINE PALATINUS (STOMATITIS): is an asymptomatic lesion associated with heavy pipe and cigar smoking usually appearing as white keratotic changes in hard palate, often combined with multiple red dots located centrally in small elevated nodule. It may disappear after smoking cessation $^{8,9}$ 9. It does reveal premalignant potential. Premalignant lesion like palatal keratosis is primarily associated with reverse smoking found mostly in South Asia ${ }^{36}$.

\section{B.ORAL PRECANCEROUS LESIONS:}

LEUKOPLAKIA AND ERYTHROPLAKIA: Oral leukoplakia is defined as a predominantly white lesion of the oral mucosa that cannot be characterised as any other definable lesion; some of these lesions will develop into cancer 37 .

Leukoplakia, which is an unscrapable white lesion of the oral mucosa is a premalignant lesion associated with development of oral cancer ${ }^{38}$. The average age of the patient is of 50-60 years, occurs predominantly in males. Smokers have a six-fold increase in the risk of developing leukoplakia compared to non-smokers ${ }^{39}$.Six European studies found smoking to be a cause in 56-97\% of leukoplakia patients. One of these studies also showed that the majority of smokers with leukoplakia (74 \%) smoked more than 20 cigarettes per day compared to $34.5 \%$ of those without leukoplakia ${ }^{39}$. Leukoplakia of the floor of mouth appeared to be significantly more often present in smokers than in non-smokers 40 (Fig.2).

Intervention studies show a regression of the lesion after the cessation of smoking 41. Smokers with leukoplakia and erythroplakia (red patches or plaques that cannot be characterised clinically or pathologically as any other conditions) have an annual cancer transformation rate of about 5\% ${ }^{42}$.Speckled leukoplakia (erythro-leukoplakia), has a cancer potential of at least $25 \%$, in some studies as high as $41 \%{ }^{14}$.

ORAL SUBMUCOUS FIBROSIS: is a precancerous condition characterized by a progressive stiffening of the oral mucosa, wherein affected persons have difficulty opening their mouths. A ten - 
year malignant transformation rate of $8 \%$ has been determined in India, where tobacco chewers routinely mix betel leaf, areca nuts, and/or slaked lime with their tobacco (Fig.3)

TOBACCO POUCH KERATOSIS: It is a white keratotic plaque, more wrinkled, has a semitranslucent appearance with tobacco encrustations over the surface and it has a microscopic appearance different from the simple excessive keratin by which leukoplakia is characterized. It is located only in areas of direct contact with snuff or chewing tobacco and is almost always completely reversible when the affected patient quits the habit. While there can be no doubt that it is a precancerous entity, its malignant potential is less than true leukoplakia by a magnitude of ten ( $4 \%$ vs. $0.4 \%$ estimated lifetime risk for leukoplakia and smokeless tobacco keratosis, respectively) 14,30 .

C. ORAL CANCER: It constitutes 2-3\% of all cancers worldwide (9). Oral cancer affects mostly middle aged or elderly people and is more common in men than in women. Cigarette smokers have two to five times higher risk of oral cancer than that of non-smokers ${ }^{43}$, the risk increasing with the number of cigarettes and years smoked. On the other hand, cessation decreases the risk ${ }^{44}$. Tobaccospecific N-nitrosamines, aromatic amines, and polycyclic aromatic hydrocarbons presented in mainstream tobacco smoke are considered the major carcinogens contributing to the risk of oral cancer from smoked tobacco products ${ }^{43}$.Carcinogens in tobacco smoke induce changes in DNA (Fig.4). Tobacco chewers also develop oral carcinomas. The oral cancer risk for these users is about 4 times greater than nonusers. A very unique low-grade oral malignancy, verrucous carcinoma, or "snuff dipper's cancer", typically develops in the exact site of chronic tobacco placement. It differs from the usual oral cancer in that it enlarges very slowly, is essentially non-metastasizing, and consists of very mature epithelial cells, i.e. has little dysplasia. The mortality rate for verrucous carcinoma is among the lowest for any cancer of the human body. Verrucous carcinoma is extremely rare (1/1,000,000 persons annually ${ }^{14}$ (Fig. 5).

Tobacco smoking and betel nut chewing with or without chewable tobacco use may induce mutations in p53 and $\mathrm{Rb}$ tumour suppressor genes 45,46 . This protein is important in regulating cell proliferation and has a role in the repair of DNA damage ${ }^{47}$. Smoking-related mutations in the gene may lead to an accumulation of DNA damage in the cells, which may play an important role in the development of cancer. Glutathione S-transferase M1 (GSTM1) and T1 (GSTT1) enzymes are both involved in the metabolism of environmental carcinogens, including tobacco-derived carcinogens. The prevalence of null genotypes of GSTM1 and GSTT1 is high among cases of oral cancer ${ }^{48}$ with both null genotypes occurring together in $60.2 \%$ of cases in one study ${ }^{49}$

SYNERGISTIC EFFECTS OF TOBACCO SMOKE AND SALIVA IN ORAL CANCER: Exposure to tobacco smoke is considered responsible for up to $90 \%$ of cases of this cancer worldwide. Free radicals, which often originate in cigarette smoke (CS) are frequently considered to be the reagents capable of triggering the process leading to malignant transformation ${ }^{50}$. A synergistic, deleterious interaction between CS and saliva has been reported, which results in the rapid destruction of biological macromolecules such as enzymes and proteins, giving it a possible pivotal role in the pathogenesis of oral cancer ${ }^{51,52}$. This lethal synergistic effect of CS and saliva is probably based on the reaction between redox-active metals in saliva and low reactive free radicals in CS(50).Aldehydes from tobacco smoke could interact with thiol compounds of salivary proteins, leading to structural and functional alterations of these molecules. It also causes salivary inactivation of enzymes 
(amylase, LDH) ${ }^{53}$. This is a novel concept recognizing that when exposed to CS, salivary behaviour is reversed and saliva loses its antioxidant capacity, becoming a potent pro-oxidant milieu ${ }^{50}$.

HAIRY TONGUE: The condition of elongated filiform papillae mimicking hair on the dorsum of the tongue is frequently seen in heavy smokers ${ }^{14}$

\section{ALTERATION OF LOCAL PHYSIOLOGY \& MICROBIOLOGY}

INCREASED SALIVARY FLOW: Nicotine from tobacco products are cholinergic agonist which acts on muscarinic receptors and affect the nervous system via acetylcholine, stimulates the salivary secretion. Certainly, intense smokeless tobacco use has been shown to result in degenerative changes of more than $40 \%$ of minor salivary glands located in the site of chronic tobacco placement, and immunoglobulin A (IgA) levels are depressed in smokers ${ }^{14}$.

BACTERIA: Smoking reduces the overall concentration of bacteria in the mouth, but the mix of oral micro flora does not appreciably alter, nor is the rate of plaque formation enhanced, at least not when differing oral hygiene levels are controlled for. Tobacco chewing however, appear to enhance the presence of several periodontal pathogens, namely Veillonella, Bacteroides, and Fusobacterium 14

CANDIDIASIS AND MEDIAN RHOMBOID GLOSSITIS: The great majority (83\%) of oral candidiasis patients are moderate to heavy smokers. Median rhomboid glossitis, a Candida-induced tongue change, is most frequently (85\%) seen in smokers and is markedly improved upon smoking cessation $^{54}$.

SINUSITIS: Tobacco smokers are much more prone to maxillary sinusitis than nonusers and this condition typically resolves or is significantly reduced when the smoking habit is discontinued. This effect is probably secondary to a tobacco-induced oedema of the sinus membranes and by diminished ciliary activity of respiratory epithelial cells. The oedema tends to narrow sinus openings or orifices while the weakened ciliary movement prevents mucous and bacterial transport out of the sinuses ${ }^{14}$.

ALTERED TASTE: Tobacco smoking increase taste thresholds thereby diminishes ability to detect various tastes and smells. Relative to taste, a dose-related association is known for bitter sensations, and to a lesser extent for salty tastes, but there appears to be little change in the ability to detect sweet or sour substances. ${ }^{14}$ Interestingly, persons who are able to quit smoking express a very strong preference for sweet foods, a feature which probably helps to explain the weight gain so commonly noted after smoking cessation ${ }^{55,56 .}$

HALITOSIS: Both smoking and chewable tobacco forms produce unpleasant breath odours or "bad breath". With smoking the halitosis is produced predominantly by the retention and subsequent exhalation of inhaled smoke in the lungs. Pipe and cigar tobacco contains more sulfur than cigarettes, hence users tend to have a more offensive halitosis than cigarette smokers 2,56 .

APHTHOUS ULCERS: Tobacco smoking seems to prevent its occurrence or diminish its effects. Aphthae frequently begin to appear or reappear in persons who stop smoking, and almost all (96\%) affected individuals are non-smokers. Canker sores are less prevalent in smokeless tobacco users 
than in nonusers. The reasons for this "protection" are unclear, but may be related to an increased mucosal keratinization or a reduced immune attack against the bacterial antigens thought to trigger ulcer formation ${ }^{57,58}$

CONCLUSION: The use of smoking and chewing forms of tobacco negatively influences oral health. Most oral consequences of tobacco use like periodontitis, sub mucosal fibrosis, oral pre-cancers and cancer etc impair the quality of life. It is the responsibility of the dental professionals to motivate the patient to quit the tobacco habit. Smoking cessation should be incorporated as an integral teaching component of the undergraduate dental curriculum, particularly with respect to the prevention and diagnosis of tobacco induced oral lesions and complications. Both dentist and physicians should collaborate in smoking cessation programmes, .There is an urgent need reduce availability of tobacco by implementing provisions of tobacco cessation act ${ }^{59}$. Everyone should emulate some states which have y banned oral forms of tobacco. Educate youth about ill effects of tobacco and prevent them from taking this habit. Early treatment of tobacco related diseases also important in preventing deaths due to tobacco related disorders.

\section{REFERENCES:}

1. Benegal V (2005). "Nicotine dependence" substance causing dependence: Manual for physicians, National drug dependence treatment outcomes. AIIMS, New Delhi, 104-120.

2. Jitendra K and Sangeeta J. Effects of tobacco on oral cavity. Journal of dental sciences 2011; 2:40-41.

3. Soben Peter Essentials of preventive and community dentistry.2003; .2nd ed, Arya (medi) publishing house, New Delhi, 472-473.

4. Bastiaan RJ, Reade PC .The effects of tobacco smoking on oral and dental tissues. Austral Dent J 1976:21; 308-315.

5. Schmidt HJ Tobacco smoke and the teeth. Stoma. 1951; 4:111-25

6. Vellappally S, Fiala Z, Smejkalova J, Jacob V and Somanathan R Smoking related systemic and oral diseases. The journal of acta medica 2007; 50:161-166.

7. Jorma Tenovuo and Kauko K. Makinen Concentration of Thiocyanate and Ionizable Iodine in Saliva of Smokers and Nonsmokers. J Dent Res. 1976; 661.

8. Johnson NW, Bain CA. Tobacco and oral disease EU-Working Group on Tobacco and Oral Health. Br Dent J 2000; 189:200-06.

9. Reibel J Tobacco and oral diseases. Update on the evidence, with recommendations. Med Princ Pract. 2003; 12: Suppl 1: 22-32.

10. Vellappally S, Fiala Z, Šmejkalová J, Jacob V and Shriharsha PInfluence of tobacco use in dental caries development. Cent Eur J Public Health 2007; 15:116-121.

11. William Ludwick and Maury Massler Relation of Dental Caries experience and Gingivitis to cigarette smoking in Males 17 to 21 Years Old J Dent Res 1952; 31:319.

12. Going RE, Hsu SC, Pollack RL, Haugh LD. Sugar and fluoride content of various forms of tobacco. J Am Dent Assoc. 1980; 100:27-33.

13. Critchley JA, Unal B Health effects associated with smokeless tobacco: a systematic review. Thorax. 2003; 58: 435-43.

14. Jerry Bouquot \& Kathy Schroeder Oral Effects of Tobacco Abuse. Journal of the American Dental Institute for Continuing Education.1992; 43:3-17. 
15. Scott DA, Singer DL Suppression of overt gingival inflammation in tobacco smokers - Clinical and mechanistic considerations. Int J Dent Hyg. 2004; 2:104-10.

16. Bastian RJ, Waite IM Effects of tobacco smoking on plaque development and gingivitis. J Periodontal1978; 49:9,480-482.

17. Tipton DA, Dabbous MK. Effects of nicotine on proliferation and extracellular matrix production of human gingival fibroblasts in vitro. J Periodontol 1995; 66: 1056-64.

18. Travis J, Pike R, Imamura T, Potempa J. The role of proteolytic enzymes in the development of pulmonary emphysema and periodontal disease. Am J Respir Crit Care Med 1994; 150:143S-146S.

19. Johnson BD, Engel D. Acute necrotizing ulcerative gingivitis. A review of diagnosis, etiology and treatment. J Periodontal 1986 57:141-50.

20. Horning GM, Cohen ME. Necrotizing ulcerative gingivitis, periodontitis, and stomatitis: clinical staging and predisposing factors Periodontal 1995; 66 :990-98.

21. Slots J, Contreras A Herpes viruses: a unifying causative factor in periodontitis? Oral Microbial Immunol 2000; 15:277-80.

22. Clarke NG, Shephard BC, Hirsch RS The effects of intra-arterial epinephrine and nicotine on gingival circulation. Oral Surg Oral Med Oral Pathol 1981; 52:577-82.

23. Grossi SG, Zambon JJ, Ho AW, et al Assessment of risk for periodontal disease. Risk indicators for attachment loss. J Periodontal.1994; 65:260-67.

24. Bergstrom J, Eliasson S and Preber H Cigarette smoking and periodontal bone loss. J Periodontal 1991; 62:242-246.

25. Anne C.R. Tanner, Ralph Kent Jr, Thomas Van Dyke, Steven T, Sonis and Lora A. Murray. Clinical and other risk indicators for early periodontitis in adults. J Periodontal 2005; 76: 573-581.

26. Gunnar Holm. Smoking as an additional risk for tooth loss. J Periodontal 1994; 65:996-1001.

27. Bergstrom J Cigarette smoking as risk factor in chronic periodontal disease. Community Dent Oral Epidemiol.1989; 17: 245-7.

28. Kinane DF, Chestnutt IG Smoking and periodontal diseases. Crit rev oral Biol Med 2000; 11:356-365.

29. Ryder MI The influence of smoking on host responses in periodontal infections.Periodontology.2000; 43: 267-277.

30. Sham ASK, Cheung LK, Jin LJ, Corbet EF The effects of tobacco use on oral health. Hong Kong Med J 2003; 9:271-77

31. Preber H, Linder L, Bergstrom J Periodontal healing and periopathogenic micro flora in smokers and non-smokers. J Clin Periodontal.1995:22:946-52.

32. Grossi SG, Skrepcinski FB, DeCaro T, Zambon JJ, Cummins D, Genco RJ Response to periodontal therapy in diabetics and smokers. J Periodontol.1996:67:1094S-1102S.

33. Bostrom L, Linder LE, Bergstrom J Influence of smoking on the outcome of periodontal surgery. A 5-year follow-up. J Clin Periodontol.1998:25:194-201.

34. Ah MK, Johnson GK, Kaldahl WB, Patil KD, Kalkwarf KL The effect of smoking on the response to periodontal therapy. J Clin Periodontol.1994: 21:91-97.

35. Grossi SG, Zambon J, Machtei EE, et al Effects of smoking and smoking cessation on healing after mechanical periodontal therapy. J Am Dent Assoc.1997:128:599-607. 
36. Mehta FS, Jalnawalla PN, Daftary DK, Gupta PC, Pindborg JJ. Reverse smoking in Andhra Pradesh, India: variability of clinical and histologic appearances of palatal changes. Int J Oral Surg .1977 :6:2:75-83.

37. Van der Waal I, Axell T. Oral leukoplakia: a proposal for uniform reporting Oral Oncol.2002:38:521-26.

38. Ma N, Tagawa T, Hiraku Y, Murata M, Ding X, Kawanishi S8-Nitroguanine formation in oral leukoplakia, a premalignant lesion. Nitric Oxide 2006:14:2: 137-43.

39. Bokor-Bratic M. Prevalence of oral leukoplakia Med Pregl.2003:56,552-55.

40. Schepman KP, Bezemer PD, van der Meij EH, Smeele LE, van der Waal. Tobacco usage in relation to the anatomical site of oral leukoplakia. Oral Dis. 2001:7, 1:25-27.

41. Banoczy J, Gintner Z, Dombi C. Tobacco use and oral leukoplakia J Dent Educ. 2001: 65:4:322-27.

42. Lee JJ, Hong WK, Hittelman WN, et al Predicting cancer development in oral

43. Leukoplakia: ten years of translational research. Clin Cancer Res.2000:6:1702-10.Winn DM. Tobacco use and oral disease. J Dent Educ. 2001: 65:4:306-12

44. Hecht SS Cigarette smoking: cancer risks, carcinogens, and mechanisms. Langenbecks Arch Surg. 2001. 391:6:603-13.

45. Jones AA general review of the p53 gene and oral squamous cell carcinoma. Ann R Australas Coll Dent Surg.1998:14:66-9.

46. Tanaka N, Odajima T, Mimura M, et al. Expression of Rb, pRb2/p130, p53, and p16 proteins in malignant melanoma of oral mucosa. Oral Oncol; 2001:37:308-14.

47. Nylander K, Dabelsteen E, Hall PA. The p53 molecule and its prognostic role in squamous cell carcinomas of the head and neck. J Oral Pathol Med 2000. 29:9:413-25.

48. Hung HC, Chuang J, Chien YC, et al Genetic polymorphisms of CYP2E1, GSTM1, and GSTT1; environmental factors and risk of oral cancer. Cancer Epidemiol Biomarkers Prev. 1997:6,901-5.

49. Nair UJ, Nair J, Mathew B, Bartsch H. Glutathione S-transferase M1 and T1 null genotypes as risk factors for oral leukoplakia in ethnic Indian betel quid/tobacco chewers. Carcinogenesis 1999:20:743-8.

50. Nagler R, Dayan D. The Dual Role of Saliva in Oral Carcinogenesis. Oncology 2006: 71:10-17

51. Nozad-Mojaver Y, Mirzaee M, Jafarzadeh A Synergistic effects of cigarette smoke and saliva. Med Oral Patol Oral Cir Bucal 2009. 14; 5:217-21.

52. Reznick AZ, Hershkovich 0 and Nagler RM. Saliva - a pivotal player in the pathogenesis of oropharyngeal Cancer. British Journal of Cancer $2004: 91: 111-118$

53. Weiner D, Levy Y, Khankin EV, Reznick AZ. Inhibition of salivary amylase activity by cigarette smoke aldehydes. Journal of physiology and pharmacology 2008; 59: suppl 6, 727737.

54. Arendorf TM, Walker DM).Tobacco smoking and denture wearing as local aetiological factors in median rhomboid glossitis. Intnl J Oral Surg $1984: 13: 411-415$

55. Rodin J). Weight change following smoking cessation: the role of food intake and exercise. Addictive Behav 1987; 12:303-317. 
56. Taste Alteration, Halitosis \& Weight Change Nilsson B Taste acuity of the human palate. III. Studies with taste solutions on subjects in different age groups. Acta Odont Scan 1979 ; 37:235-252.

57. Axéll T, Henricsson V. Association between recurrent aphthous ulcers and tobacco habits. Scan J Dent Res1985; $93: 239-242$.

58. Bennet KR, Reade PC Salivary immunoglobulin A levels in normal subjects, tobacco smokers, and patients with minor aphthous ulceration. Oral Surg Oral Med Oral Path 1982; 53:461-465.

59. Tobacco control act http://www.qp.gov.sk.ca/documents/english/Statutes/Statutes/t141.pdf

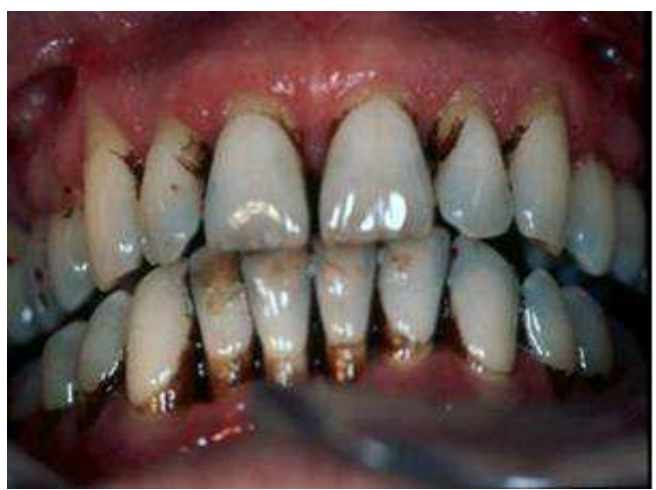

FIG 1) Teeth stains \& Periodontitis in smokers

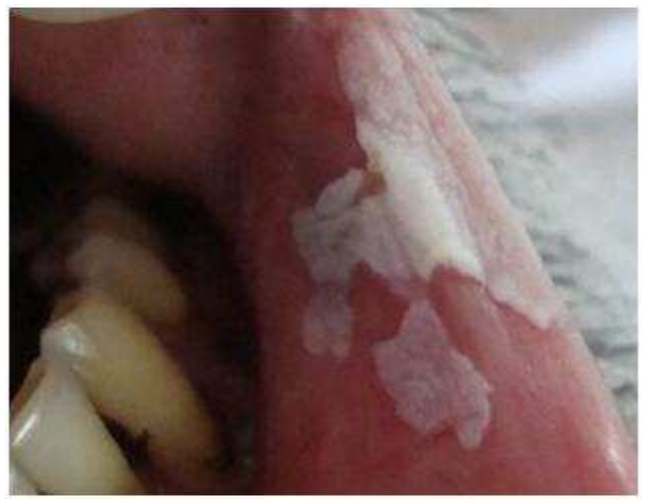

FIG 2) Oral leukoplakia 


\section{REVIEW ARTICLE}

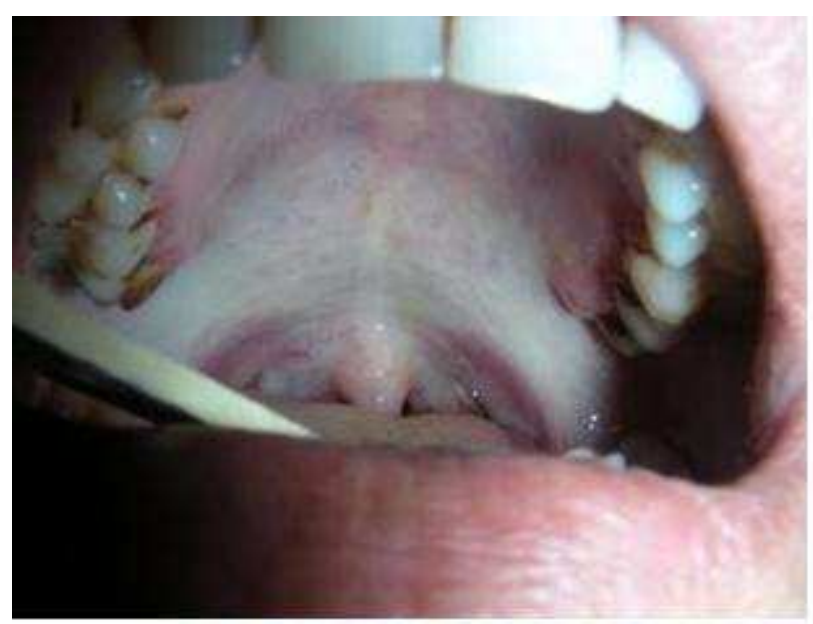

FIG 3) Oral submucous fibrosis

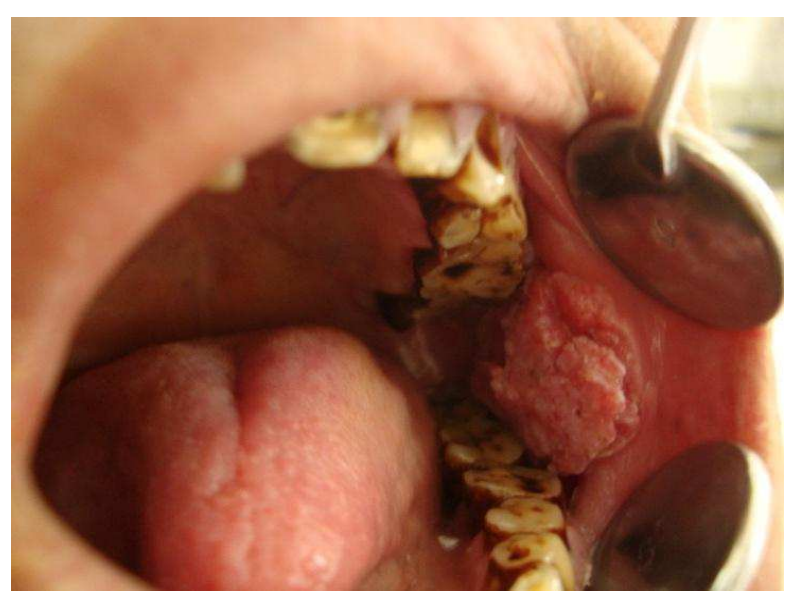

Fig 4) Oral squamous cell carcinoma

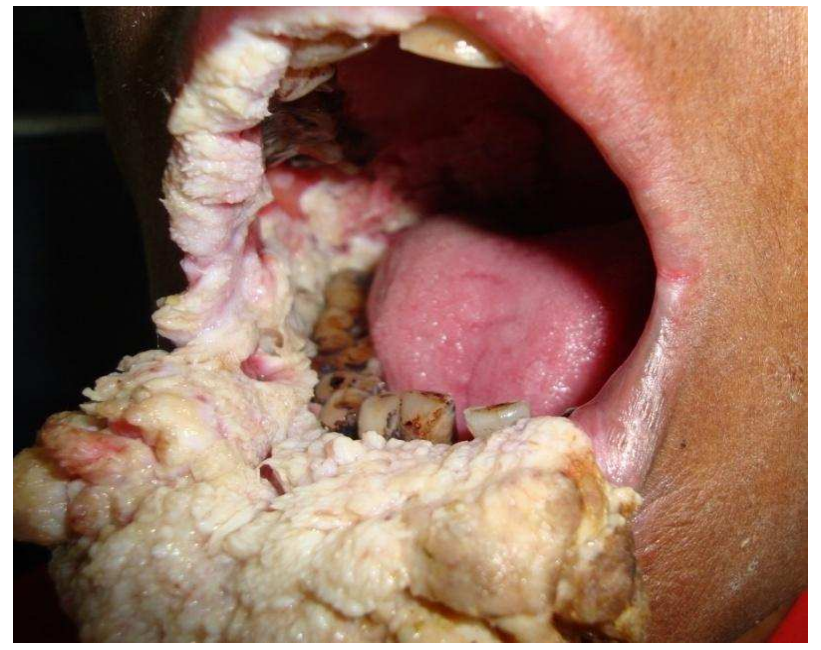

Fig 5) Verrucous carcinoma 